\title{
Construction Worker Fatigue Prediction Model Based on System Dynamic
}

\author{
Tri Joko Wahyu Adi ${ }^{1, *}$, Lila Ayu Ratnawinanda ${ }^{1}$ \\ ${ }^{1}$ Department of Civil Engineering, Institut Teknologi Sepuluh Nopember, Indonesia
}

\begin{abstract}
Construction accident can be caused by internal and external factors such as worker fatigue and unsafe project environment. Tight schedule of construction project forcing construction worker to work overtime in long period. This situation leads to worker fatigue. This paper proposes a model to predict construction worker fatigue based on system dynamic (SD). System dynamic is used to represent correlation among internal and external factors and to simulate level of worker fatigue. To validate the model, 93 construction workers whom worked in a high rise building construction projects, were used as case study. The result shows that excessive workload, working elevation and age, are the main factors lead to construction worker fatigue. Simulation result also shows that these factors can increase worker fatigue level to $21.2 \%$ times compared to normal condition. Beside predicting worker fatigue level this model can also be used as early warning system to prevent construction worker accident
\end{abstract}

Keyword: Construction Safety; Worker Fatigue; Prediction model; System dynamic

\section{Introduction}

The construction industry has a very important role in the development of a country. The unique characteristics and the dynamic nature of the construction industry lead to a dangerous condition and prone to accidents. Construction industry becomes the riskiest industries compared to other industry, because construction industry is based on the workers as its main power source. The use of man power become one of the reason, why construction industry suffered occupational accident more than other industries. As seen in Fig. 1, the number and rate of construction worker accidents in 2013 is very high. In Indonesia, the death rate due to accidents in the in 2015 increased by $4 \%$ compared to 2014 [1]. The problem of occupational safety and health are often ignored. Unsafe behaviour of workers is the main cause of $88 \%$ of accidents in workplace in construction industry, $10 \%$ due to unsafe conditions, and $2 \%$ are unpreventable [2]. The unsafe workplace conditions significantly determined the types of accidents and severity of injuries, while safe work equipment was essential to the complexity of the construction activities. The unsafe condition of the equipment refers to hazards that are not detected in the security apparatus.

\footnotetext{
*Corresponding author: trijokowahyuadi@gmail.com
} 


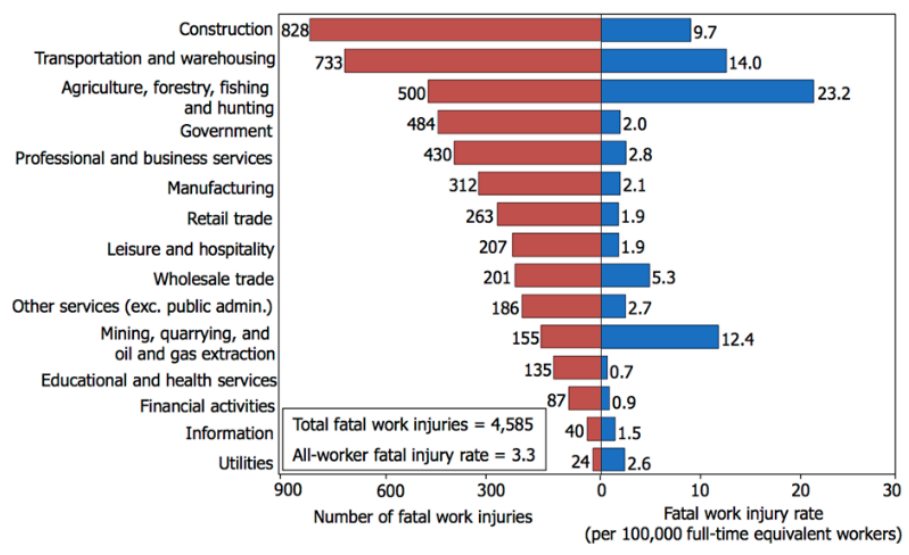

Fig. 1. Fatal occupational accident among industries

Construction accidents can negatively impact the project, including the disruption of work schedules, cost overruns, psychological effects for workers and company reputation. Tight schedule of the project forces the construction worker to work in a high pressure condition. These situations can trigger stress and fatigue to construction worker. Excessive fatigue level will trigger the occurrence of human error and unsafe act which lead to worker accidents $[3,4,5,6]$. This paper aims to propose worker fatigue prediction model based on system dynamic. Beside predicting worker fatigue level this model can also be used as early warning system to prevent construction worker accident

\subsection{Factors causing work fatigue}

Construction accidents are caused by three main factors, namely: unsafe acts, unsafe conditions and unsafe equipment $[3,4,5,6]$. Factor of human error can lead to unsafe acts. According to statistics, $80 \%$ of the incidence of human error, $50 \%$ of them are caused by fatigue [4]. Fatigue is the body's protective mechanisms to avoid further damage. Fatigue is a condition characterized by feelings of fatigue, decreased alertness, and decreased worker productivity. According to Oesman \& Simanjuntak [7], fatigue can be caused by internal factors and external factors. Internal factors are the characteristics of workers, such as gender, age, weight, height, nutritional status and lifestyle; while external factors include workload and working conditions $[2,7,8,9,10]$, revealed that the excess load factors greatly affect worker fatigue. $32 \%$ of workers who lift heavy items between $75-100 \mathrm{~kg}$ will experience back pain.

Age increases susceptibility to respiratory disease. Respiratory problems are also triggered by an unhealthy lifestyle, such as smoking and alcohol consumption. Empirical data also show that age will affect psychomotor ability and cause a decrease in muscle strength. Productive age with maximum muscle strength is between 25-50 years. At age 45, the strength of the worker remaining only $70 \%-80 \%$ [4,7]. At every $0.4{ }^{\circ} \mathrm{C}$ increase in body temperature, an increase in pulse rate 5 times/ minute. So that the effect on worker fatigue is $1 / 0.4 \times 5=12.5$ times/minute. $(12.5 / 60) \times 100 \%=20.8 \%$. Based on interview with occupational health and safety expert in construction project, alcohol and cigarettes also affect the fatigue of worker by $10 \%$ [8].

According to Maurits, as noted in the Limbong's paper [11] external factors that causing fatigue associated with the work environment; such as weather, wind pressure, noise, and sun exposure. While fatigue associated with work stress, include: long working hours (overtime), rest periods and improper work shift arrangements [8,12]. Working at 
height makes the job needs more oxygen. Lack of oxygen made unstable working conditions and reduced vision. As a result, could endanger workers. Workers falling from a height, such as the roof and scaffolding, is the largest contributor of accidents in the construction industry [13]. Rest will eliminate fatigue. Rest done at break time, will return the stamina of workers by $70 \%$ [14]. In normal working hours, the lighting depends on the elevation of the workplace. According to Chang, sun Chuang and Hsu, changes in floor elevation (6 to 10 floors) will have an effect of lighting degradation of 3\%. [8]. High ambient temperature and humidity can cause the heart to pump more blood. As the result the pulse rate increases 4-10 times per minute. If it is taken an average of 7.5 times / min at a temperature of $29^{\circ} \mathrm{C}$ it gives an effect of $12.5 \%$

\subsection{Method for measuring work fatigue}

Prediction of fatigue, is done by measuring several indicators of fatigue. In general, the methods for measuring fatigue is divided into six groups; they are: 1. measurement based on the quality and performance of workers, 2. measurement based on subjective impressions, 3. measurements using electroencephalography (EEG), 4. measurement based on subjective observation of eye blink frequency, 5. measurement of psychomotor, and 6 . mental testing. Measurement of work fatigue is conducted before work, during work and after work activities. Based on these tests, levels of fatigue and sources of work fatigue can be inferred [2].

Measurement of fatigue can also be done with the direct measurement method (EMG). EMG uses indicators of fatigue such as changes in heart rate, changes in body temperature, changes in breathing rate, changes in visual ability and changes in muscle strength, to predict level of fatigue $[8,15]$. Measuring the level of worker fatigue, can interfere the activities of the workers. Workers feel disturbed by the equipment installed, resulting in bias result due to the perceived inconvenience of workers. However, by doing objective measurement, realistic and real-time results can be obtained $[8,15$, $16,17,18,19,20,21,22,23]$.

\section{Model Construction}

\subsection{Causal Loop Diagram (CLD)}

This paper proposes construction worker fatigue prediction model based on system dynamic (SD). System dynamic is a computer-aided approach to understand the nonlinear behavior of complex systems over time. More detail information of SD can be read in [24]. In this model, system dynamic is used to represent correlation among variable and to simulate the fatigue level of construction worker. 93 construction workers from 3 high-rise building construction project in Indonesia were used as respondents. To validate the model a high rise office building project in Surabaya-Indonesia is used as case study. Causal Loop Diagram which represent the correlation among variables is derived from indepth literature review and validated by occupational health and safety expert. In CLD, variables are divided into internal and external factors. Internal factors consist of: worker characteristic such as age, lifestyle, height, weight of the worker and physical condition such as body temperature, breathing, pulse and vision. External factors consist of: project condition such as workload, work elevation, equipment noise, weather condition, wind velocity, sun exposure, ambient temperature, and worker schedule such as work shift arrangement, over time and recess. Based on internal and external factors, a Causal Loop Diagram which represent the relationship among variables and stock flow diagram are presented in Fig. 2 and Fig. 3 respectively. 


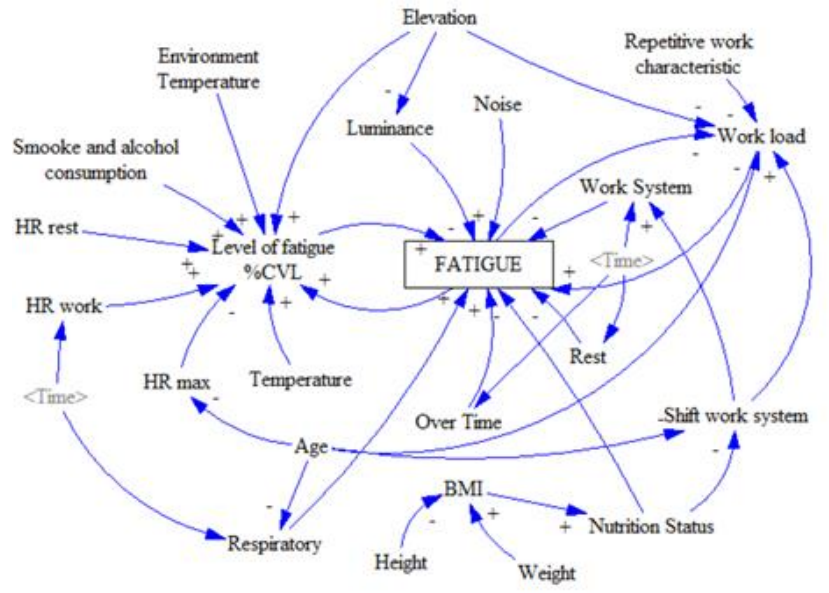

Fig. 2. Causal Loop Diagram for construction worker fatigue model

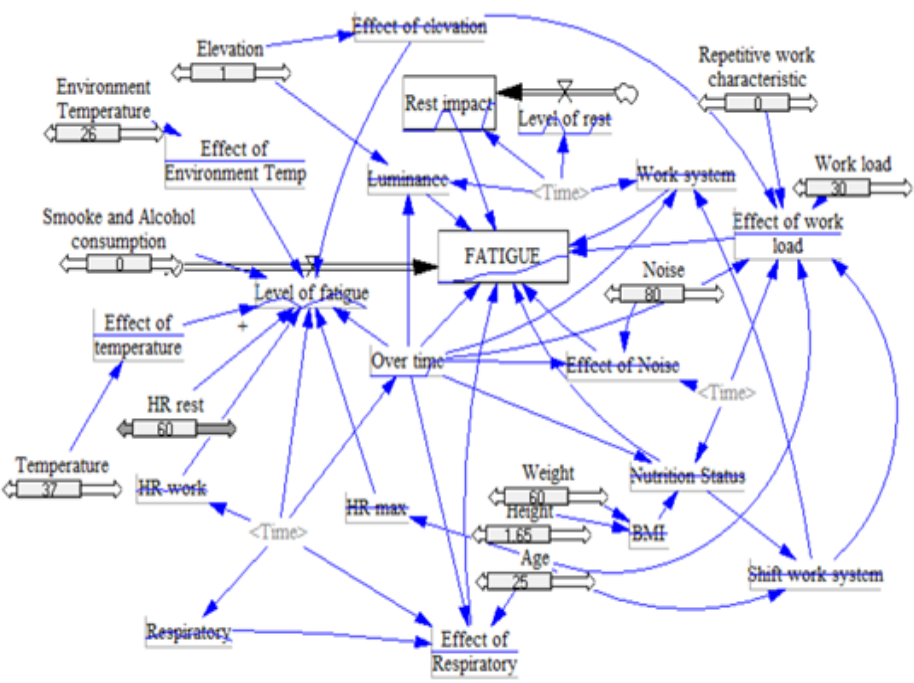

Fig. 3. Stock flow diagram of Construction worker fatigue model

Fatigue level of the worker is predicted using Percentage of Cardio Vascular Load (\%CVL) indicator. The classification of the CVL condition can be seen in Table 1. In SD simulation, Total fatigue level of construction workers is formulated in equation 1.

Table 1. Classification of \% CVL related to worker fatigue

\begin{tabular}{|l|l|}
\hline \multicolumn{1}{|c|}{$\% \mathbf{C V L}$} & \multicolumn{1}{c|}{ Classification of CVL } \\
\hline$<30 \%$ & No Fatigue \\
\hline $30 \%-60 \%$ & Need to be recharged \\
\hline $60 \%-80 \%$ & Allowed to work in short period \\
\hline $80 \%-100 \%$ & Need special treatment \\
\hline$>100 \%$ & Not allowed to work \\
\hline
\end{tabular}

Total $\% C V L=\% C V L$ internal factor effect $+\%$ CVL external factors effects 


\section{Model Implementation}

\subsection{Data collection}

To collect data, internal and external sensor are used. Sensor node A (Internal/Body sensor) are used for collecting real time worker data such as: heart beat data, body temperature, respiration and working elevation. While sensor node B (External/Environmental sensor) are used to collect real time environmental information such as, noise, and luminance. The mechanism of the sensor is depicted in Fig. 4.

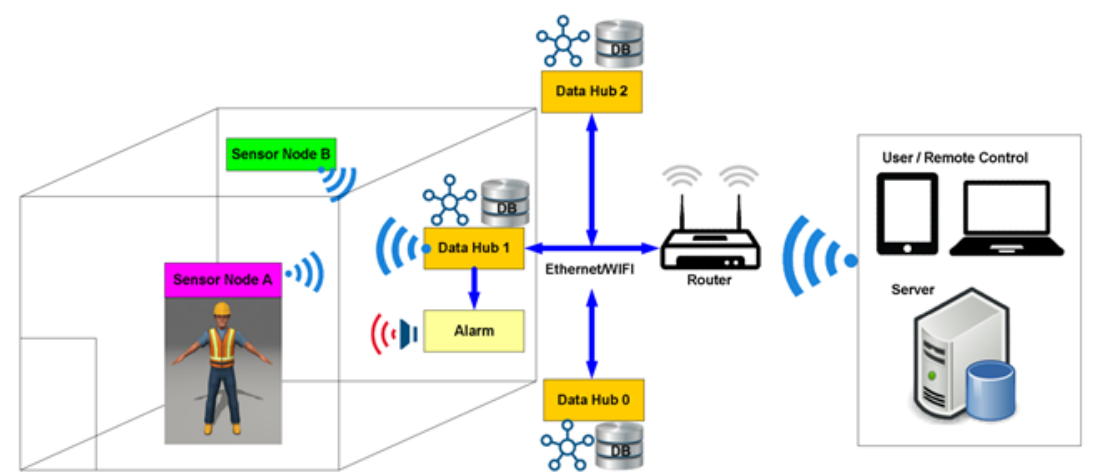

Fig. 4. Sensor system Network

$80 \%$ of 93 construction workers ware used to build model equation. Input data from body sensors and environmental sensors are collected by Data Hub 1. These information is then stored as database in Data Hub 2. Further process is done by calculating level of worker fatigue, using SD model proposed in Figure 3 and Equation 1. Final result is transmitted to alarm when level of fatigue higher than $60 \%$.

\subsection{Model validation}

To validate the proposed model, 20 construction workers from a high rise building project are used as case study. Validation is done by comparing worker fatigue prediction and observation result from sensor data in the normal condition. Data were taken every hour from construction worker and converted to \%CVL. As seen in Fig. 5, the proposed model provides quite good prediction of $\% \mathrm{CVL}$. The average error is $12.6 \%$.

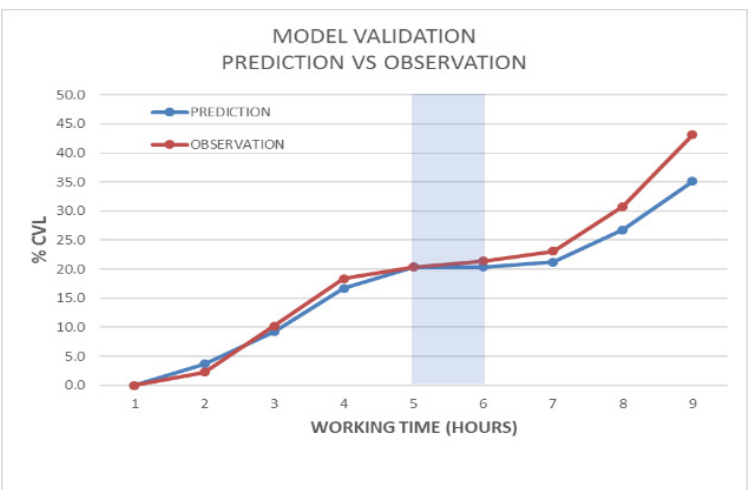

Fig. 5. Proposed model validation result 


\subsection{Simulation scenarios}

To implement the proposed model, 2 simulation scenarios are designed to see the impact of internal and external factor to the construction worker fatigue level. First scenario is designed for comparing worker fatigue in normal load condition (load $<40 \mathrm{~kg}$ ), versus worker fatigue with excessive load (varies load between $40-75 \mathrm{~kg}$ ). The second scenario is designed by increasing value of internal and external factors such as age ( $>40$ years old) and working elevation ( $>6^{\text {th }}$ floor). In both scenarios, every worker is given break for 1 hour. The scenarios result can be seen in figure 6 to 7 respectively.

In Fig.5, it can be seen that after 2 hours the fatigue level of construction worker with excessive load increase significantly. The average of fatigue level increase $64.3 \%$.

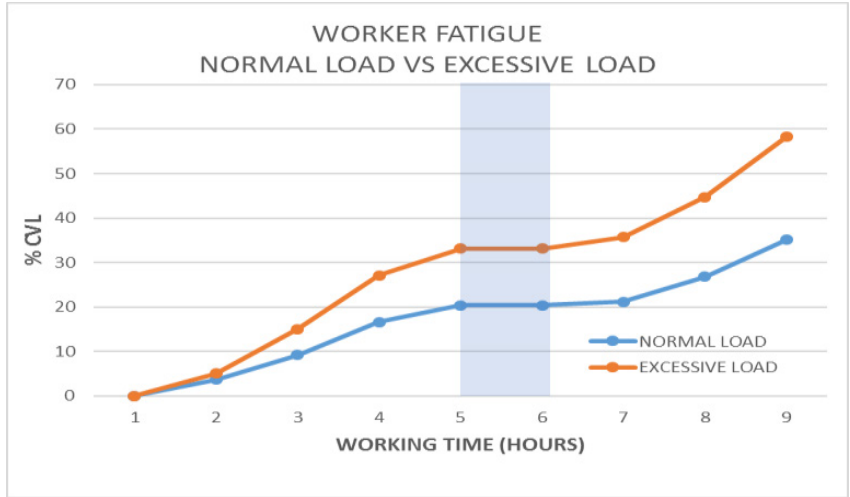

Fig. 6. Excessive load effect to worker fatigue

Fig. 7 shows the change in worker fatigue rate compared to normal conditions. Model simulations with changes in internal factors (age, nutrition status, body temperature and smoke and alcohol consumption) showed increase in fatigue rate $39.5 \%$. Based on the scenario on the changes of external factors (work system, work load, noise, luminance, environment temperature, over time and elevation), worker fatigue level increase $60.7 \%$. While the effect of simultaneous changes between internal and external factors the fatigue rate increase $74.2 \%$. It can be concluded that the more complex the changes in internal and external variables, fatigue level increased significantly.

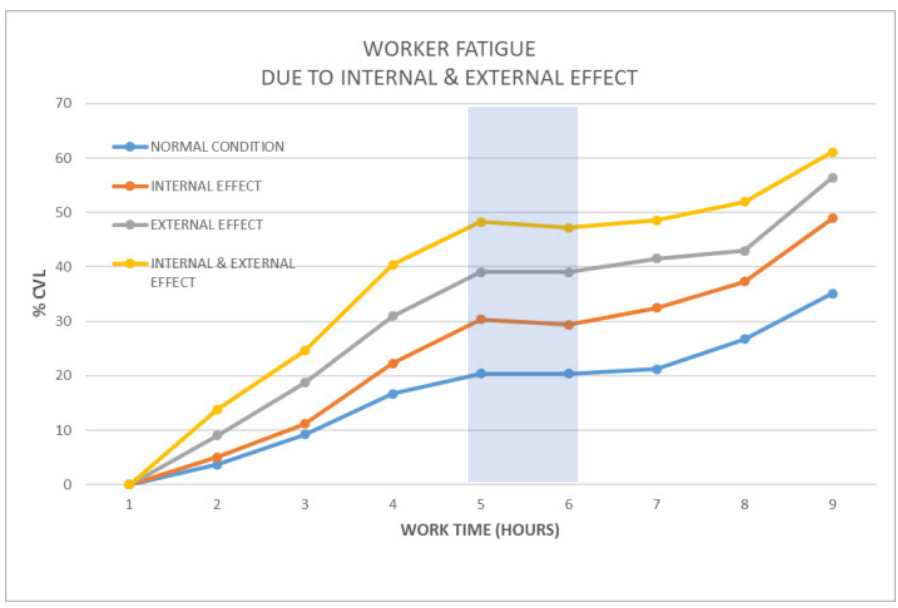

Fig. 7. Level of fatigue due to Internal and external factors 


\section{Conclusion}

This model is under development as part of construction occupational health and safety monitoring system. The proposed model presents the relationship among internal and external variables that cause fatigue of construction worker. To predict the level of fatigue, percentage of Cardio Vascular Load (\%CVL) is used as main indicator. Simulation result shows that excessive work load, working elevation, and age are the factors that most influencing construction worker fatigue. It also shows that the effect of external factors is higher compared to internal factor.

\section{References}

[1] Anto, A. Erma, S. J. Industrial Eng. 7 (1), pp. 83-90, (2010)

[2] Cahyani, W. D. J., J. Knowledge and Tech., (2010)

[3] Cheng, C.W. Lin, C.C. Leu, S.-S. Safety Science 48, 436-444., (2010)

[4] Fadel, M. Muis M. Russeng, S. S., Master Thesis, unhas.ac.id, (2014)

[5] Han, S. Lee S. Mora, F. P. J. Comput Civil Eng. 27 (6), 635-644. (2013)

[6] Haslam, R., Hide, S., Gibb, A., Pavitt, T., Atkinson, S., \& Duff, A. Appl. Ergon. 36 (4), 401-415., (2005)

[7] Oesman, T. I. Simanjuntak, R. A. Proc. 11th Nat'l Conf. of Indonesian Ergon. Society, (pp. 268-276), (2011)

[8] Chang, F. L. Sun, Y. M. Chuang, K. H. Hsu, D. J. Appl Ergon, 1(6). (2008)

[9] Javaid, N., Faisal, S., Khan, Z., Nayab, D., \& Zahid, M. IEEE 8th Int'l Conf. on Broadband and Wireless Comp., Compeigne, France, (2013)

[10] Irma, M., Russeng, S. S., \& Wahyuni, A. Master thesis, Hasanudin university, (2014).

[11] Limbong, N. Y. Josephus, J. Kawatu, P. A. Master thesis, Sam Ratulangi university, (2015)

[12] Hallowell, M. R.,Professional Safety, (2010)

[13] Goh, Y. M. Sa'adon, N. F. J Constr Eng Manag. 141 (16)., (2015)

[14] Indonesian labor law, Indonesian Labor Law, article 13, (2013)

[15] Wang, D. Dai, F. Ning, X. J. Constr Eng Manag. 141(6), (2015)

[16] Fang, D. Jiang, Z. Mingzong, Z. Han, W. Saf Sci 73, 80-91., (2015)

[17] Lin, Y. H. Ho, S. C. Lai, C. Y. Proc. 19th Congress of the IEA, (pp. 1-6) Melbourne., (2015)

[18] Mocci, F. Serra, A. Corrias, G. Occup Environ Med 58, 267-271., (2001)

[19] O'Neill, C. Panuwatwanich, K. Proceedings of the 4th International Conference on Eng. Proj., and Prod. Manag. (EPPM, 2013), (pp. 993-1005)., (2013)

[20] Fang, Y. C. Dzeng, R. J. Creative Construction Conf. 2014, CC2014 (pp. 147-156). Procedia Engineering, (2014)

[21] Hsu, D. Sun, Y. M. Chuang, K., Juang Y. Chang, F. Saf Sci 46, 833-843. (2008)

[22] Isaac, S. Edrei, T., Auto. in Constr. 63, 66-78. (2016)

[23] Li, H. Chan, G. Huang, T. Skitmore, M. Tao T. Y. Luo, E., et al., Automat Constr. 55, 58-65., (2015)

[24] Katsuhiko, O. Pearson Education Limited, (2014) 